\title{
Spinal Cavernous Hemangioma in a Pediatric Patient - A Case Report
}

\section{Roman $A^{1-3 *}$, Mesquita Filho PM $^{1-5}$, Manzato LB ${ }^{1,2}$, De Carli $F^{5}$, Schwingel $D^{6}$ and Oliveira TA}

${ }^{1}$ Neurosurgery Department, Hospital da Cidade de Passo Fundo, Brazil

${ }^{2}$ Neurology and Neurosurgery Service (SNN), Brazil

${ }^{3}$ Medical School UPF (Universidade de passo Fundo), Passo Fundo, Brazil

${ }^{4}$ Medical School of Faculdade Meridional (IMED), Passo Fundo, Brazil

${ }^{5}$ Academic League of SNN (LASNN), Passo Fundo, Brazil

${ }^{6}$ Pathology Institute of Passo Fundo, Passo Fundo, Brazil

\section{Introduction}

Cavernous malformations, also termed "cavernous hemangiomas," "cavernous angiomas," and "cavernomas", terms that may carry different histological variations, are benign developmental anomalies composed of endothelium lined vascular channels. They are found throughout the Central Nervous System, but rarely occur in the spine [1]. Spinal cavernous hemangiomas are vascular malformations with a reported incidence of $5 \%$ to $12 \%$ of all spinal vascular abnormalities. Approximately $3 \%$ of spinal cavernous hemangiomas are intradural, usually with an intramedullary location. Epidural cavernous hemangioma of the spine, account for approximately $4 \%$ of these vascular epidural lesions [2].

Prior to 1990 only 10 surgically treated cases were reported in the literature [3], by 2003 this number had increased [4] with few cases located in the cervical and thoracolumbar spine [5,6]. Due to their rareness, the variable clinical symptoms and variable MR findings, diagnosis of these lesions is often difficult [5].

\section{Case Report}

We report the case of a one-year and eight-month-old male patient, presenting with progressive paraparesis and hypotonia, posteriorly presenting with a severe coagulopathy. The patient never developed adequate ambulation, according to his parents.

On physical examination, blue sclera was depicted as a finding not previously mentioned, just as paraparesis with diminished reflexes of the lower limbs, having the tonus and reflexes of upper limbs preserved.

On further investigation, an important coagulopathy, especially

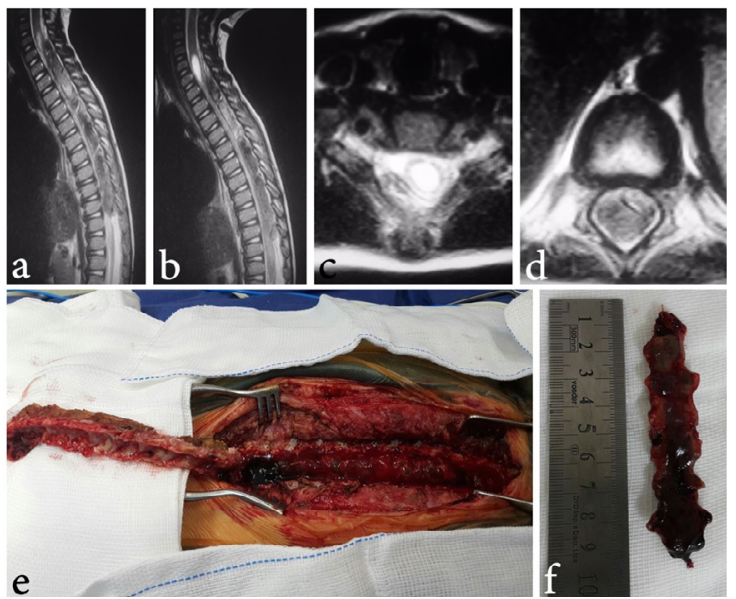

Figure 1: (a) Sagittal T2WI MRI showing an extensive spinal heterogenous lesion. (b) Sagital T2WI MRI demonstrating proximal intramedullary lesion, compatible with syringomyelia. (c) Axial T2WI MRI of the cervical spine, demonstrating an apparent extra-axial heterogenous lesion, and the dilation of a cystic lesion of the the compressed spinal cord. (d) Axial T2WI MRI of the thoracic spine, showing a large intracanal extra-axial lesion, compressing the spinal cord. (e) trans-operative image of the extensive laminectomy and in situ lesion. (f)- Extensive resected hemorrhagic lesion. with prolonged prothrombin timing and diminished coagulation activity, displaying preserved platelets counting was found. MRI exams demonstrated an extensive cervico-thoracic intracanal lesion, extending from the seventh cervical vertebra to the eleventh thoracic vertebral body, heterogenous on T1-weighted images as well as on T2weighted images, exerting compression on the cervico-thoracic spinal cord, and also a hyperintense proximal intramedullary lesion that resembled proximal seringomyelia (Figure 1).

The patient was submitted to an extensive laminectomy, posterior to frozen plasma administration, and microsurgical resection of the extra-medullary, extra-dural lesion, which trans-operatively permitted the appreciation of extensive vascularization with medialto-large caliber vessels, especially in the proximal and distal portions of the lesion. Especial care was undertaken to preserve spinal cord vascularization, and proximal, as well as distal, arterial feeders were initially coagulated and controlled, and latter venous drainage was surgically obstructed, allowing bipolar coagulation of the tumor lesion and microsurgical removal with further safety and less hemorrhage. The bone defect was closed with laminoplasty and special care was undertaken to preserve facet anatomy, as well as interspinal ligaments, albeit the most proximal segment was carefully resected, in order to perform the laminectomy and microsurgical resection of the lesion, and since it was a continuous space occupying lesion, it was not possible to perform intermittent fenestration for hematoma removal as initially planned. Post-operatively, the patient presented a favorable recovery, with slight improvement of the lower limbs muscle strength, as well as reflexes on examination and post-operative MRI showed spinal cord decompression (Figure 2).

Histological result confirmed an extramedullary, epidural lesion, consistent with an extensive cavernous hemangioma (Figure 3). The patient is currently followed closely for hemangioma recurrence and spinal deformities, and genetic investigation is underway.

\section{Discussion}

Vascular tumors may be benign or malignant in nature. The benign tumors include hemangiomas, vascular ectasia, and bacillary angiomatosis. The malignant tumors include angiosarcomas and hemangiopericytomas [7]. Cavernous hemangiomas, which are otherwise known as cavernomas, although this term may confer

${ }^{*}$ Corresponding author: Dr. Alex Roman, Department of Neurosurgery, Hospital da Cidade de Passo Fundo, Passo Fundo, Brazil, Tiradentes Street, 295, ZIP Code 99010-260, Passo Fundo, Brazil, E-mail: alexroman_@hotmail.com

Received October 28, 2015; Accepted November 20, 2015; Published November 23, 2015

Citation: Roman A, Mesquita Filho PM, Manzato LB, De Carli F, Schwingel D, et al (2015) Spinal Cavernous Hemangioma in a Pediatric Patient - A Case Report. J Spine S6: 002.doi:10.4172/2165-7939.S6-002

Copyright: $\odot 2015$ Roman A, et al. This is an open-access article distributed under the terms of the Creative Commons Attribution License, which permits unrestricted use, distribution, and reproduction in any medium, provided the original author and source are credited. 


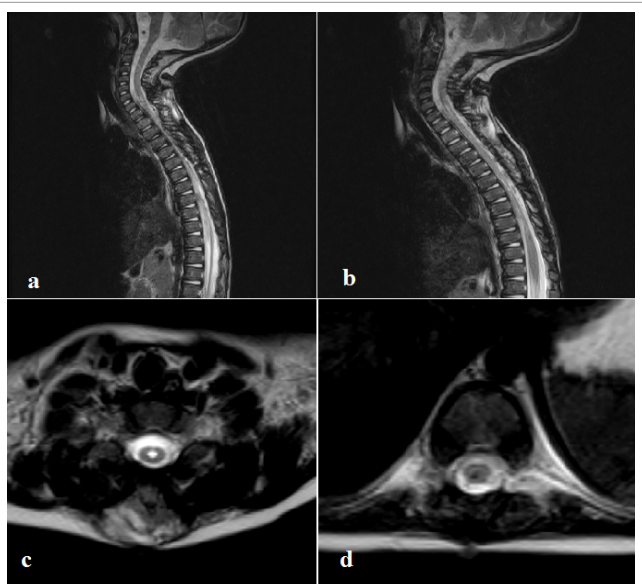

Figure 2: (a and b) Post-operative sagital T2-WI MRI showing spinal cord decompression, after microsurgical resection of intracanal space occupying lesion. (c and d) Post-operative axial T2-WI MRI showing spinal cord decompression, with reduction of pre-operative syringomyelia.

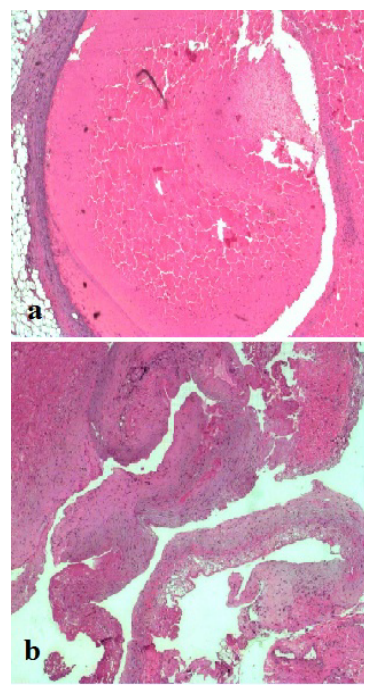

Figure 3: (a) Hematoxylin and Eosin (HE) stain showing cavernous space lined with endothelial cells. (b) HE stain showing median to large cavernous hemangioma vessel space filled with hemorrhagic substrate.

confusion between cavernous angiomas and hemangiomas, are benign vascular lesions which occur commonly in the skin, liver and in the superficial and the deep soft tissues. A cavernous hemangioma consists of irregular vascular spaces which are lined by a single layer of endothelium. Most of the cavernous hemangiomas of the spine originate from the abnormal development of the periradicular vessels [8].

CNS cavernous hemangiomas are rare and they are composed of closely packed, large, sinusoid like vascular channels with little or no intervening nervous tissue. They may occur anywhere in the CNS, but they favor the cerebral hemisphere [9]. In the spine, cavernomas are found far more frequently in the vertebral bodies and when they involve the peridural space, they occur primarily within the spinal cord [10].

The first case of an intradural extramedullary spinal cavernoma was reported by Hadlich [10] in 1903 as an incidental finding at autopsy, with the first clinical case being described almost 20 years later by Roger et al. $[11,12]$ Cavernomas usually present during the second and fifth decades of life. Cavernomas occur in both familial and sporadic forms, and three human chromosomes are responsible for these inherited forms [13]. The central nervous hemangiomas are associated clinical syndromes like the Mafucci's syndrome, which is a hemangioma with multiple enchondromas, the Kasabach-Merritt syndrome which is consumption coagulopathy with a hemangioma and the blue rubber bleb nevus syndrome with numerous hemangiomas in the skin and in the gastrointestinal tract [8].

Their clinical presentation corresponds to their location and nature. The space occupying effect on the neural tissue is the main cause of the progressive general non-specific symptoms. The latter may also be caused by diapedisis hemorrhage. Symptoms include back, neck, and/or spinal pain, sensorimotor deficits, paraparesis, bowel and urinary disturbance, and altered reflexes. Brown-Sequard syndrome and progressive cord dysfunction are also reported [2]. Progressive myelopathy caused by typical microhemorrhages and perifocal gliosis probably explains the neurological decline of affected patients. Risk of profuse hemorrhage ranges between $1.4 \%$ and $4.5 \%$ per patient per year, increasing to $66 \%$ per patient per year in patients with a previous history of hemorrhage. Due to low tolerance of the medulla to a mass lesion, patients frequently present with progressive focal sensorimotor deficits often combined with intensive radicular or central pain [14]. Recurrent accumulation, bleeding, and reabsorbance cycles of the cavernous lesion cause symptoms of various intensity. In the longterm, this process leads to enlargement, fibrosis, and calcification of the lesion itself. Microhemorrhages may further obstruct and thrombose the vascular canals that again may lead to necrosis of the thin vessel walls and may cause further hemorrhages [2].

MRI is helpful if blood and its breakdown products are found within the lesion and it is the only method that allows a presumptive preoperative diagnosis. When a well-demarcated, heterogeneous mass is found in the intracanal space of the spine, neuroradiological characteristics should be carefully studied because despite the rarity of haemangiomas, these lesions do occur in this location [15]. Spinal cavernous hemangiomas have characteristic features different from other spinal cord tumors and vascular malformations on MRI. The presence of mixed subacute and chronic hemorrhage, evident by mixed high and low-signal intensity components may be characteristics of these lesions. The presence of a webbed core of mixed signal intensity circumscribed by a border of hypointensity (macrophage uptake of hemosiderin) in T1- and T2-weighted images is highly suggestive of cavernous malformations $[16,17]$.

The optimal treatment for cavernous hemangioma of the spine is microsurgical en-bloc resection of the entire mass. Surgical procedures may be technically difficult, due to the formation of dense adhesions between the cavernous hemangioma and the nerve roots. In some cases, dissection of the nerve roots that are assumed to be the origin of the mass is unavoidable [2]. Embolization has no role in the treatment of most cavernous hemangiomas of the spine [16] and no adjuvant therapy is needed [18].

\section{Conclusion}

Spinal cavernous hemangiomas are extremely rare. The clinical outcome depends largely on the patient's preoperative neurological status, and optimal treatment consists of total excision of the lesion with careful microsurgical technique. Based on a thorough and extensive review of the cases reported in the literature, it is thought that patients presenting with severe preoperative neurological signs will have the best chance of neurological improvement with microsurgical excision of the tumor or decompression [16].

The reason for presenting this case is its extreme low incidence 
and complexity, which may render early diagnosis further difficult, thus delaying its treatment and, lastly, diminishing possibility for neurological recovery. The patient was treated with surgery and genetic investigation is currently underway.

\section{References}

1. Oppenlander ME, Kalani MY, Dickman CA (2012) Spinal and paraspinal gian cervical cavernous malformation with postpartum presentation. J Neurosurg Spine 16: 447-451.

2. Mataliotakis G, Perera S, Nagaraju S, Marchionni M, Tzerakis N (2014) Intradural extramedullary cavernoma of a lumbar nerve root mimicking neurofibroma. A report of a rare case and the differential diagnosis. Spine $J$ 14: e1-e7.

3. Pagni CA, Canavero S, Forni M (1990) Report of a cavernoma of the cauda equina and review of the literature. Surg Neurol 33: 124-131.

4. Nozaki K Inomoto T, Takagi Y, Hashimoto N (2003) Spinal intradura extramedullary cavernous angioma. Case report. J Neurosurg 99: 316-319.

5. Rachinger J, Buslei R, Engelhorn T, Doerfler A, Strauss C (2006) IntraduralExtramedullary Cavernous Hemangioma of the Left Motor Root C7 - Case Report and Update of the Literature. Zentralbl Neurochir 67: 144-148.

6. Ozturk, Mesut (2015) Thoracic spinal epidural capillary-cavernous hemangioma causing back pain. The Spinal Journal: official journal of the North American Spine Society 25: 155-158.

7. Robbins, Cotran (2010) Pathologic Basis of disease. 8e: 520-525.

8. Sulochana S, Sundaram M (2012) Cavernous hemangioma of the spinal cord: a rare case. J Clin Diagn Res 6: 1781-1782.
9. Vogiht K Yasargil MG (1976) Cerebral cavernous haemangiomas or cavernomas: incidence, pathology, localization, diagnosis, clinical features and treatment. Review of the literature and report of an unusual case. Neurochir (Stuttg) 19: 59-68.

10. Guthkelch AN (1948) Haemangiomas involving the spinal epidural space. J Neurol Neurosurg Psychiatry 11: 199-210.

11. Hadlich R (1903) Ein Fall von Tumor Cavernosus des Rueckenmarks mit besonderer Beruecksichtigung der neueren Theorien ueber die Genesis des kavernom. Virchows Arch 172: 429-444.

12. Roger H, Paillas JE, Bonnal J, Vigouroux R (1951) [Angiomas of the spinal cord and nerve roots]. Acta Neurol Psychiatr Belg 51: 491-495.

13. Kivelev J, Ramsey CN, Dashti R, Porras M, Tyyninen O, et al. (2008) Cervica intradural extramedullary cavernoma presenting with isolated intramedullary hemorrhage. J Neurosurg Spine 8: 88-91.

14. Kivelev J, Niemelä M, Hernesniemi J (2010) Outcome after microsurgery in 14 patients with spinal cavernomas and review of the literature. J Neurosurg Spine 13: 524-534.

15. Crispino M, Vecchioni S, Galli G, Olivetti L (2005) Spinal intradura extramedullary haemangioma: MRI and neurosurgical findings. Acta Neurochir (Wien) 147: 1195-1198.

16. Er U, Yigitkanli K, Simsek S, Adabag A, Bavbek M (2007) Spinal intradura extramedullary cavernous angioma: case report and review of the literature. Spinal Cord 45: 632-636.

17. Spetzler RF, Detwiler PW, Riina HA, Porter RW (2002) Modified classification of spinal cord vascular lesions. J Neurosurg 96: 145-156.

18. Acciarri N, Padovani R, Pozzati E, Gaist G, Manetto V (1992) Spinal cavernous angioma: a rare cause of subarachnoid hemorrhage. Surg Neurol 37: 453-456.
This article was originally published in a special issue, Advanced Techniques in Spine Surgery handled by Editor(s). Dr. Alessandro Landi, University of Rome, Italy 